\title{
Modeling and Optimization of Decentralized Microgrid System for St. Martin's Island in Bangladesh
}

\author{
Md. Ruhul Amin ${ }^{1}$ Rajib Baran Roy ${ }^{2}$ and Md. Mahmudul Hasan ${ }^{3}$ \\ ${ }^{1}$ Lecturer, ${ }^{2}$ Assistant Professor, Department of Electrical and Electronic Engineering \\ ${ }^{3}$ Assistant Professor, Department of Electronic and Communication Engineering \\ University of Information Technology and Sciences, Dhaka-1212, Bangladesh \\ ruhul.amin@uits.edu.bd
}

\begin{abstract}
St. Martin's Island is a little Island in the Bay of Bengal about $9 \mathrm{~km}$ far from the main land of Bangladesh. Nearly 5000 residents live there and fishing is their primary livelihood and as a tourist spot there are many lodges and rest houses. Since the Island is far away from the convenential national grid connection is almost unachievable even in future as a result of its geographical location. Locally installed diesel generator is used to provide electricity to inhabitants is established by power development board of Bangladesh but now it is not in operation. In this paper, an effort has been made to model a microgrid by means of hybrid electricity generation system for a small society of the Island. This system incorporates an arrangement of solar $P V$, wind turbine, storage battery, biogas and diesel generator. HOMER is software for optimization of renewable based amalgamative distributed generation systems has been used to find out the preeminent technical effective renewable based energy efficient system for 650 family units. Sensitivity analysis is also completed to perceive the impact of solar insolation, PV investment cost and wind speed and diesel fuel price on the optimum result. During peak load the convenential diesel generator is switched on after covering demand by renewable source. The results of the propose system shows that due to emphasize on renewable energy sources the greenhouse gas can be minimized and this proposed system produces $12000 \mathrm{~kg}$ of carbon-dioxide, $32.2 \mathrm{~kg}$ of carbon-monoxide and $23.8 \mathrm{~kg}$ of sulfur dioxide per year which is comparatively less than the average produced greenhouse. This system produces carbon-dioxide emission of approximately12000kg per year whereas $700 \mathrm{~kW}$ diesel generator produces $413 \mathrm{~kg}$ per hour.
\end{abstract}

Keywords: Microgrid; Distributed Energy Resources; Distributed Generation; PV; Wind; Greenhouse Gas

\section{Introduction}

St. Martin's Island is a small Island and area of only 8 kilometer square in the northeastern part of the Bay of Bengal, about $9 \mathrm{~km}$ south of the tip of the Cox's BazarTeknaf peninsula and forming the southernmost part of Bangladesh. It is about $8 \mathrm{~km}$ west of the northwest coast of Myanmar, at the mouth of the Naf River. St Martin's Island is one of the most beautiful Island for Tourist in Bangladesh where grid connected electric system for the inhabitants will not be possible to set up even in future. Diesel, kerosene and wood are the main fuels for fulfilling the energy demand. Solar and wind resources are the hybrid options for the Island. Saint Martin's Island is located on the southern-most tip of Bangladesh, roughly between $20^{\circ} 34^{\prime}-20^{\circ} 39^{\prime} \mathrm{N}$ 
and $92^{\circ} 18^{\prime}-92^{\circ} 21^{\prime} \mathrm{E}$ and 17 kilometers off Taknaf, the most southern main land of Bangladesh. The Island is very much resourceful with massive biological diversity such as existing fauna and flora Coral, Mollusk, Fish, Amphibian, Turtle, Snail, Bird and Mammals. Besides above coconut tree is the important cash crop [1]. A survey was done by the Sustainable Rural Energy (SRE) program of Local Government Engineering Department (LGED) in 2004 and documented that the population of the Island is approximately 5000 where the majority of them are fisherman and they belong to about 650 families. The yearly electric energy demand was found about 318MWh [2]. There is a $30 \mathrm{~kW}$ diesel generator in St. Martins Island launched by PDB, but it is not in operation now [3]. People meet up there energy demand all the way through kerosene, coconut palm or by other biomass plants. Some of the commercial shops and hotels meet their electricity demand by diesel generator.

Recent power systems face three serious challenges: energy crisis, reliability issue of traditional power system and the higher requirement of power quality and reliability. Meanwhile, the development of Distributed Energy Resources (DERs) has reached the bottleneck of stability impacts of having Distributed Generation (DG) on the grid such as voltage fluctuations, protection desensitizing, and so on. The paybacks of microgrids primarily focus on improving local security, reliability and healthiness to meet the requirement of privileged level of supply stability, making greater utilization of renewable energy and clean energy [4-5]. Moreover, for remote areas, the long distance electricity transmission and the fossil fuel transportation are complicated, costly and impractical, and DERs rarely provide the Uninterruptible Power Supply (UPS). But microgrids can convene the requirement of high quality and reliability more economically and efficiently. As a result, microgrids exert a pull on interest of worldwide experts, companies and governments.

The Island has a good potential of distributed sources of solar and wind energy resources. But till now there has no such activity to use these resources. Therefore HOMER (Hybrid optimization Model for Electric Renewables) [6], a software developed by National Renewable Energy Laboratory (NREL), USA for micro-power optimization model, has been used to find out the finest energy efficient renewable based hybrid system options for the Island [7]. It contains a number of energy component models and evaluates suitable technology options based on cost and availability of resources. The Island has a prospective quality of solar and wind possessions. In this sense, HOMER software has been used to find out the most excellent energy efficient renewable based hybrid system options for the Island. The software designs an optimal configuration to serve the desired electric loads. To design the optimum system HOMER performs thousands of hourly simulations. HOMER also performs sensitivity analysis to see the impact of solar insolation, PV investment cost, and wind speed and diesel fuel price on the cost of energy [8].

\section{Microgrids}

The Consortium for Electric Reliability Technology Solutions (CERTS) first proposed the definition of microgrids: CERTS Microgrid concept believes an aggregation of loads and micro-sources operating as a single system providing both power and heat. The majority of the micro-sources must be power electronic based to provide the required flexibility to guarantee operation as a single collective system. This control flexibility permits the CERTS Microgrid to present itself to the bulk power system as a single controlled unit that meets local requirements for reliability and security [9]. Not completely united even if the definitions of microgrids are, it is 
generally recognized that a microgrid, which is made of multiple DERs together with DGs and Distributed Storage Systems (DSSs), autonomous load centers, control and protection systems, can drive both in grid-connected and islanded modes, and also seamlessly switch between the two modes, enhancing the robustness of distribution system, facilitating greater utility of renewable energy, increasing energy efficiency and the level of local dependability required by customers' loads [10].

In general, remote microgrids in distant areas or Islands used to heavily rely on local power generation based on diesel or natural gas, because long distant and thus exclusive transportation make the electrification of off-grid remote communities uneconomic and slowly developed [11], while some distant areas are abundant of renewable energy, such as wind energy, solar energy and biomass energy.

The remote microgrid is a probable solution for electrification of off-grid remote communities by coupling optimally energy storage divisions and DGs in combination with an optimal dispatching strategy. The basic configuration is shown in figure 1 . The basic DGs and distributed storage can be selected and accustomed according to local natural conditions and power requirements [12]. Combined Heat and Power (CHP) systems can also be linked to remote microgrids to provide both electricity and heat for achieving maximum benefits for local energy need.

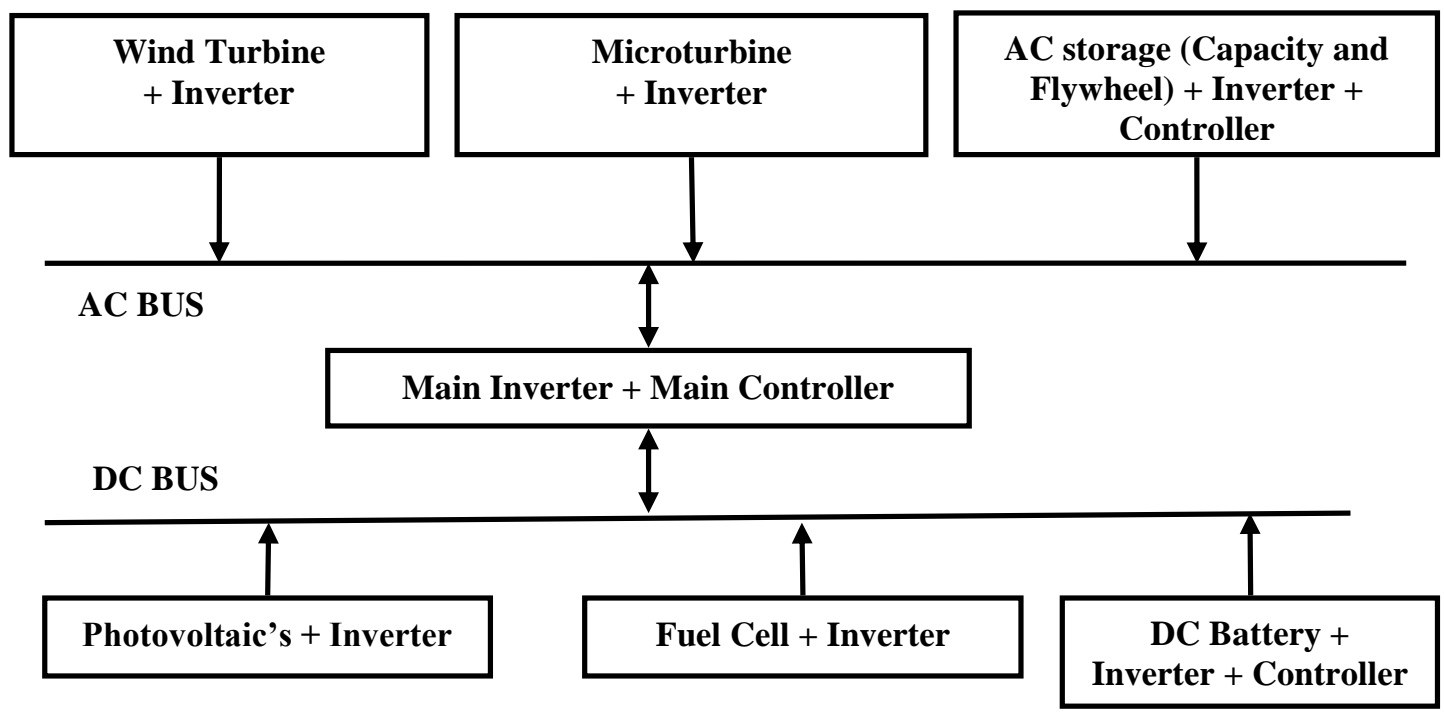

Figure 1. Configuration of decentralized microgrid

To build a reliable and economic electrification of remote areas, the key is to construct a remote microgrid, including power management, real-time control and protection system. The main purposes of the Power Management Strategy (PMS) of microgrids for the DG units are to 1) effectively share real and reactive power supplies of loads among the DG units, 2) rapidly respond to disturbances and fluctuations DSSs, 3) pair DSSs with DGs and find out the charge and discharge of DSSs, and 4) resolve the final power generation set-points of the DG units to equilibrium power and restore frequency of the system [13].

The optimal transmitting strategy based on mathematical model and optimization algorithm can decrease the microgrid lifetime cost and emission, which has been demonstrated by a remote community example located in the northern part of the Canadian province of Ontario [14]. Another power management strategy restrain of 
three parts: 1) Pre-scheme is based on past date of periodic loading profiles and optimization strategy; 2) Daily plan is based on weather forecast and probable load consumption; 3) Hourly observation is based on monitor device and simulation [15]. A three-step methodology is proposed, containing of local scopes, microgrids and virtual power plants considering different optimization objectives [16].

\section{Distributed energy sources in St. Martin's island}

There is no earth measurement data of solar radiation for the Island. But from the NASA satellite, it has been found that the annual solar insolation over St Martin is $4.84 \mathrm{kWh} / \mathrm{m}^{2} /$ day [7]. An estimation of solar insulation on horizontal surface has been done by using well known Angstrom Correlation and the sunshine hour data of Teknaf, Bangladesh, Meteorological Department, the neighboring meteorological station from St Martin's. Also a method has been build up by DLR, Germany which is a mixture of DLR/SUNY-model output for Global Horizontal Insolation (GHI) is sampled for $10 \mathrm{~km}$ spatial resolution, and the calculated data has been composed from the SWERA Geospatial Toolkit for Bangladesh, developed under the SWERA project [17]. Table 1 shows the values of monthly solar insulation on horizontal surface for St Martin, observed from NASA for the period of 10 years (1983-1993) and estimated values from Teknaf sunshine data also for 10 years (1992-2001). DLR method used three years (2000, 2002 and 2003) satellite data for cloud cover, aerosol optical depth, water vapor to calculate GHI.

Table 1. GHI values for St Martin's Island

\begin{tabular}{|c|c|c|c|}
\hline Month & NASA & Estimated(from sunshine) & DLR \\
\hline Jan & 4.84 & 4.00 & 4.63 \\
\hline Feb & 5.46 & 4.44 & 5.04 \\
\hline Mar & 6.41 & 5.37 & 5.62 \\
\hline Apr & 6.48 & 5.87 & 6.47 \\
\hline May & 5.96 & 5.43 & 4.94 \\
\hline June & 3.60 & 4.10 & 3.39 \\
\hline Jul & 3.62 & 3.87 & 3.31 \\
\hline Aug & 3.69 & 3.95 & 3.78 \\
\hline Sept & 4.34 & 4.09 & 3.96 \\
\hline Oct & 4.72 & 4.21 & 4.28 \\
\hline Nov & 4.42 & 3.72 & 4.54 \\
\hline Dec & 4.54 & 3.75 & 4.16 \\
\hline Annual & 4.84 & 4.40 & 4.50 \\
\hline
\end{tabular}

For Wind resources information, Bangladesh Council for Scientific and Industrial Research (BCSIR) has calculated wind speed for the period of three years (1999 2001) at a height of around 30 meters above the ground level. Table 2 shows the monthly averaged measured wind speed at 30 meters height and the NASA values for the same location at $10 \mathrm{~m}$ height for terrain similar to airport. It has been found that wind speed leaves to maximum and minimum at around 10 o'clock in the night and morning of local time respectively. 
Table 2. Wind speed data for St Martin's Island

\begin{tabular}{|c|c|c|}
\hline Month & NASA (10m) & Measured (30m) \\
\hline Jan & 3.27 & 5.03 \\
\hline Feb & 3.39 & 4.70 \\
\hline Mar & 3.57 & 4.24 \\
\hline Apr & 3.67 & 3.79 \\
\hline May & 3.89 & 5.07 \\
\hline June & 6.27 & 6.17 \\
\hline Jul & 6.35 & 5.56 \\
\hline Aug & 5.64 & 5.78 \\
\hline Sept & 4.05 & 4.47 \\
\hline Oct & 3.27 & 4.11 \\
\hline Nov & 3.24 & 3.53 \\
\hline Dec & 3.10 & 4.11 \\
\hline Annual & 4.14 & 4.71 \\
\hline
\end{tabular}

Biomass could be an alternative for energy sources. There are more than 10000 coconut trees and 470 different kinds of fruit trees including some domestic animal in the Island [1]. Seven tidal gauge stations were set up by Bangladesh University of Engineering and Technology (BUET) for the feasibility study of tidal energy [18]. Due to increasing population the primary load is increasing day-by-day also. On the other hand, renewable source of energy is limited at St. Martin's Island. To meet the progressive demand or primary load, convenential diesel generator can be solution when pick load is appeared at evening in summer.

\section{Hybrid Options Analysis}

A hybrid energy system usually consists of a primary energy sources running in parallel with standby secondary energy storage units. HOMER has been used to optimize the best energy efficient system for St Martin considering different load and wind, PV, biomass, diesel generator, storage battery and converter combination. Figure 2 shows the schematic diagram the propose scheme of microgrid as implemented in HOMER simulation tool. HOMER simulates the operation of a system by assembling energy balance calculations for each of the 8,760 hours in a year. For each hour, HOMER evaluates the electric demand in the hour to the energy that the system can supply in that hour, and calculates the streams of energy to and from each component of the system. For systems that include batteries or fuel-powered generators, HOMER also decides for each hour how to operate the generators and whether to charge or discharge the batteries. 


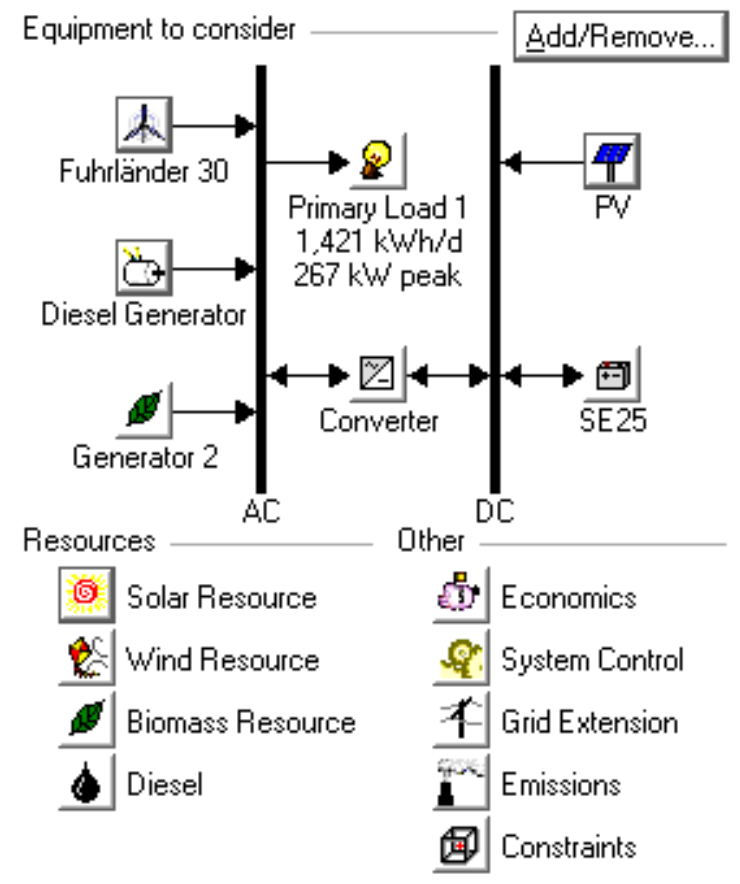

Figure 2. Proposed microgrid system in HOMER

HOMER performs these energy balance calculations for each system configuration that anybody wants to consider. Then it determines whether a configuration is feasible, i.e., whether it can meet the electric demand under the conditions that have been specified and estimates the cost of installing and operating the system over the lifetime of the project. The system cost calculations account for costs such as capital, replacement, operation and maintenance, fuel and interest.

\subsection{Electric load}

A typical load system shows Table 3 for 650 families in the remote areas has been considered for the analysis. Monthly average hourly load demand (Bangladesh point of view) has been given as an input of HOMER and then it creates daily and monthly load profile for a year is shown in Figure 3. It has been found that for this system each home user consume energy around $1421 \mathrm{kWh}$ /day with a peak demand of nearly $267 \mathrm{~kW}$.

Table 3. Appliances for single home user

\begin{tabular}{|l|l|l|}
\hline Appliance & Quantity & Capacity (W) \\
\hline Florescence Light & 1950 & 15 \\
\hline TV & 250 & 80 \\
\hline Fan & 1950 & 50 \\
\hline Refrigerator & 250 & 80 \\
\hline
\end{tabular}

\subsection{Renewable resources}

For wind monthly averaged $(1999$ - 2001) measured data from BCSIR have been used along with the information of height $=30 \mathrm{~m}$, elevation $=3 \mathrm{~m}$ surface roughness $=$ $0.01 \mathrm{~m}$. HOMER synthesized these monthly average data based on the other parameters such as Weibull factor " $\mathrm{k} "=1.8$, Autocorrelation factor (randomness in wind speed) $=$ 
0.90 , Diurnal pattern strength (wind speed variation over a day) $=0.25$, Hour of peak wind speed $=22$ to generate hourly data for a year. Figure 4 shows average hourly wind speed for 1 year.

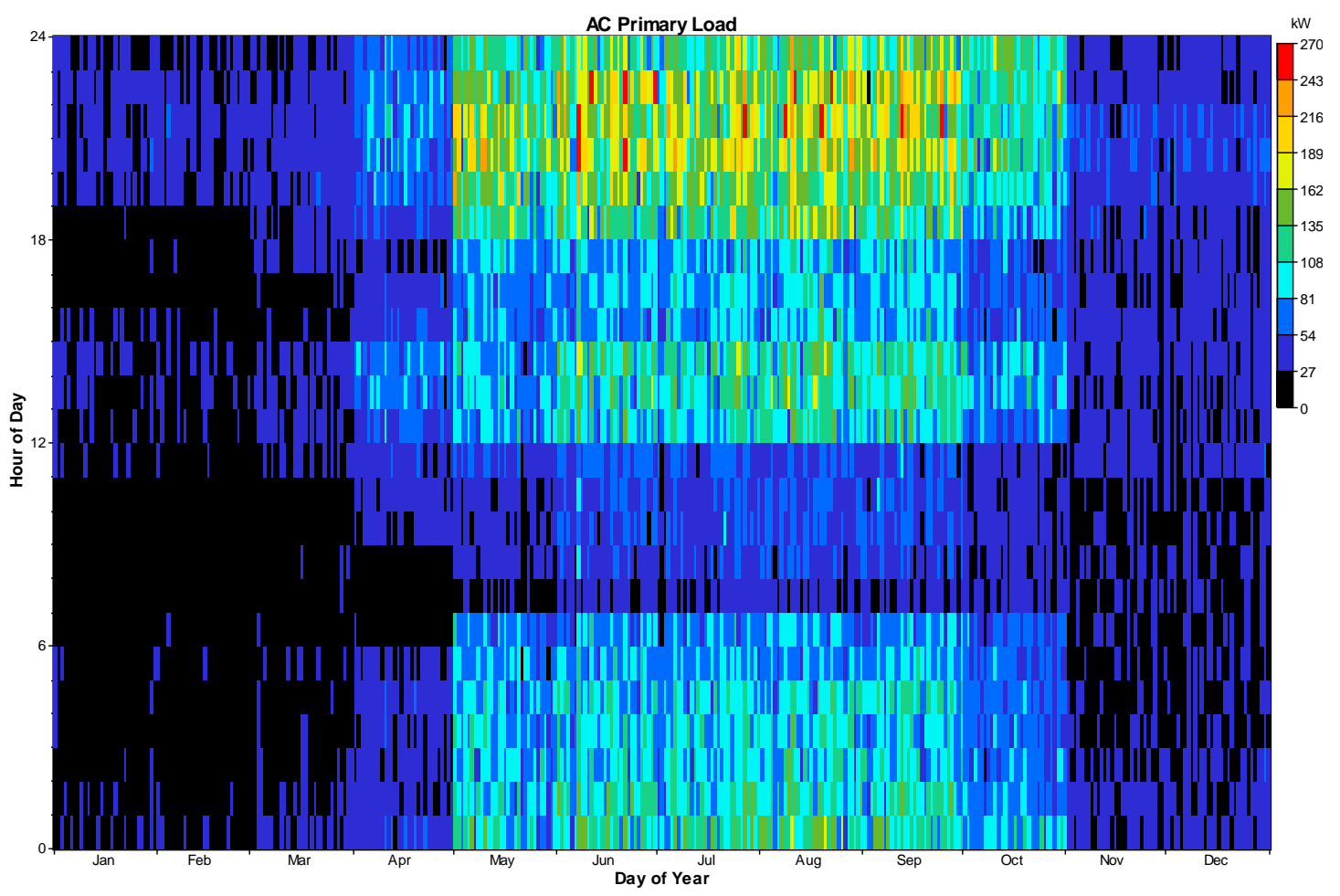

Figure 3. Monthly average hourly load profile for total system.

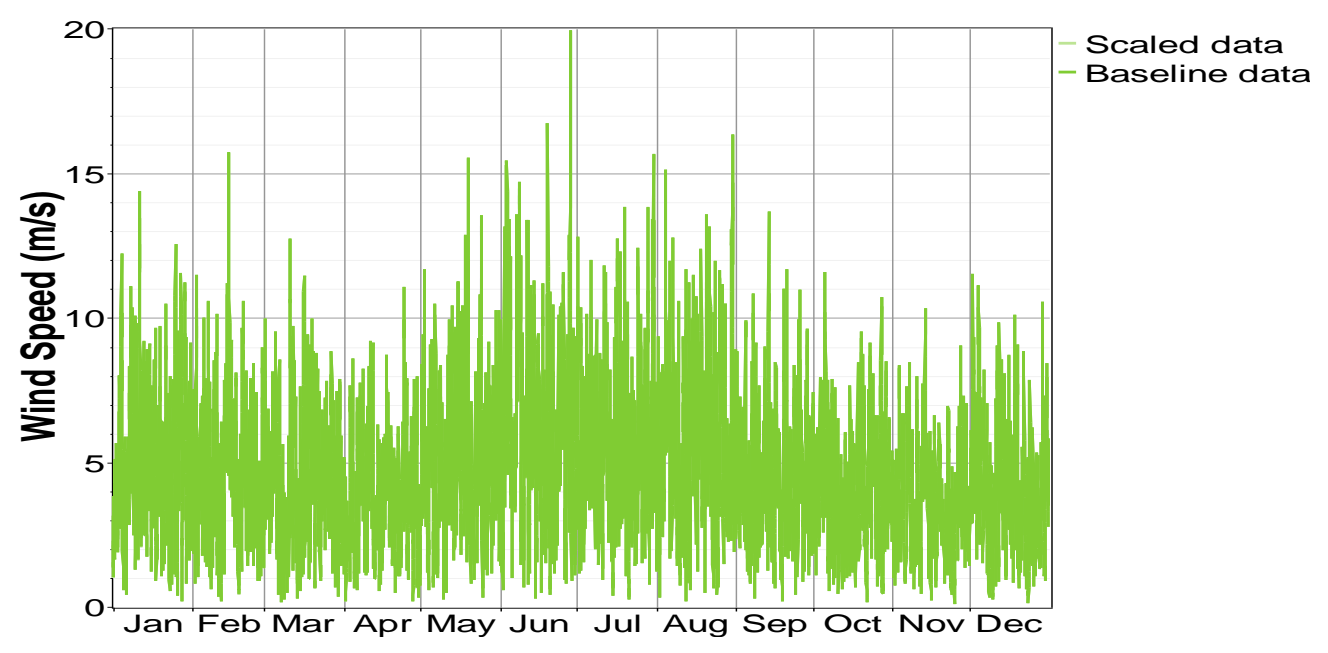

Figure 4. average hourly wind speed for 1 year 


\subsection{Renewable resources}

For wind monthly averaged (1999 - 2001) measured data from BCSIR have been used along with the information of height $=30 \mathrm{~m}$, elevation $=3 \mathrm{~m}$ surface roughness $=$ $0.01 \mathrm{~m}$. HOMER synthesized these monthly average data based on the other parameters such as Weibull factor " $\mathrm{k} "=1.8$, Autocorrelation factor (randomness in wind speed) = 0.90 , Diurnal pattern strength (wind speed variation over a day) $=0.25$, Hour of peak wind speed $=22$ to generate hourly data for a year. Figure 4 shows average hourly wind speed for 1 year.

\subsection{Photovoltaic module}

The cost of PV module including installation has been considered as $160 \mathrm{BDT} / \mathrm{W}$ for Bangladesh. Life time of the modules has been taken as 25 years and the tilted angle is controlled by horizontal axis weekly. (1 USD $=75$ BDT, 2014)

\subsection{Wind generator}

For this analysis a Fuhrlander AG (FL 30) turbine with a capacity of $1.5 \mathrm{KW}$ has been considered for containing characteristics of high efficiency at St. Martin's wind speed. The cost of the turbine with tower and installation has been considered as 750000BDT / turbine.

\subsection{Diesel generator and other}

In case of higher demand of electricity, the renewable source and storage battery are not adequate for meeting the load. As a result a generator $500 \mathrm{~kW}$ is used during peak load. Moreover, from the depositing biomass, approximately $100 \mathrm{~kW}$ generator can be run. These sources of energy are optional and standby in condition. Diesel generator may cost approximately 150000BDT and in this analysis fuel cost of 80BDT/Liter is used. In addition, from bio wastage processing to conversion of electricity, total system may cost of around 20000BDT include maintenance cost of 25BDT/working hour.

\subsection{Battery with controller:}

As the system considered the DC load only, battery and controller were also as a main part of the system. Battery from Beacon Power (Model: Beacon Smart Energy 25, nominal V: $825 \mathrm{~V}$ nominal capacity: $30.3 \mathrm{Ah}, 25 \mathrm{kWh}$ ) has been used at a cost of 30000BDT / battery with charge controller. The recharge able grind tied batteries have same more extra operation and maintenance of 12000BDT/year.

\section{Simulations and Data Analysis}

Analysis shows the cost of energy (KWh) is low for the system which is the combination of 650 households. Figure 5 shows that there are several options for running the proposed microgrid system. Figure 6 shows the monthly electric production for single optimization mode for this proposed microgrid system. Table 4 shows that the green house gas emission from the proposed system. 


\begin{tabular}{|c|c|c|c|c|c|c|c|c|c|c|c|}
\hline \multicolumn{12}{|l|}{ Results Optir } \\
\hline \multicolumn{8}{|c|}{ Double click on a system below for simulation results. } & \multicolumn{2}{|c|}{$C$ Categorized $C$ Overall } & \multirow{2}{*}{$\begin{array}{l}\text { Export... } \\
\text { Total } \\
\text { NPC }\end{array}$} & \multirow{2}{*}{$\begin{array}{l}\text { Details.... } \\
\begin{array}{c}\operatorname{COE} \\
(\mathrm{S} / \mathrm{kWh})\end{array}\end{array}$} \\
\hline \⿻上丨 & $\begin{array}{c}\mathrm{PV} \\
(\mathrm{kW})\end{array}$ & FL30 & $\begin{array}{l}\text { Label } \\
(\mathrm{kW})\end{array}$ & $\begin{array}{l}\text { Label } \\
(\mathrm{kW})\end{array}$ & SE25 & $\begin{array}{l}\text { Conv. } \\
\text { (kW) }\end{array}$ & \begin{tabular}{|l|} 
Efficiency \\
Measures
\end{tabular} & $\begin{array}{l}\text { Initial } \\
\text { Capital }\end{array}$ & \begin{tabular}{l|l} 
Operating & \\
Cost (\$/yr) & \\
\end{tabular} & & \\
\hline 国图 & 200 & 3 & 700 & 100 & 500 & 1200 & No & $\$ 2,140,000$ & 144,836 & $\$ 3,991,487$ & 0.602 \\
\hline 圂 & 200 & 3 & 700 & 100 & 500 & 1200 & Yes & $\$ 2,140,000$ & 144,836 & $\$ 3.991 .487$ & 0.602 \\
\hline 图 & 200 & 2 & 700 & 100 & 500 & 1200 & No & $\$ 2,130,000$ & 145,914 & $\$ 3,995,274$ & 0.603 \\
\hline 国 & 200 & 2 & 700 & 100 & 500 & 1200 & Yes & $\$ 2,130,000$ & 145,914 & $\$ 3,995,274$ & 0.603 \\
\hline 圂 & 200 & 2 & & 100 & 500 & 800 & No & $\$ 2,100,000$ & 148,405 & $\$ 3,997,108$ & 0.603 \\
\hline 囷 & 200 & 2 & & 100 & 500 & 800 & Yes & $\$ 2,100,000$ & 148,405 & $\$ 3,997,108$ & 0.603 \\
\hline 囷 & 200 & 2 & & 100 & 500 & 1200 & No & $\$ 2,110,000$ & 148,670 & $\$ 4,010,505$ & 0.605 \\
\hline 国 & 200 & 2 & & 100 & 500 & 1200 & Yes & $\$ 2,110,000$ & 148,670 & $\$ 4,010,505$ & 0.605 \\
\hline 娄 & 300 & 3 & & 100 & 520 & 400 & No & $\$ 2,200,000$ & 144,407 & $\$ 4,046,004$ & 0.611 \\
\hline 囷 & 300 & 3 & & 100 & 520 & 400 & Yes & $\$ 2,200,000$ & 144,407 & $\$ 4,046,004$ & 0.611 \\
\hline 田 & 300 & 1 & 700 & 100 & 520 & 400 & No & $\$ 2,200,000$ & 144,751 & $\$ 4,050,397$ & 0.611 \\
\hline 国 & 300 & 1 & 700 & 100 & 520 & 400 & Yes & $\$ 2,200,000$ & 144,751 & $\$ 4,050,397$ & 0.611 \\
\hline 图 & 300 & 2 & 700 & 100 & 520 & 400 & No & $\$ 2,210,000$ & 144,360 & $\$ 4,055,409$ & 0.612 \\
\hline 网 & 300 & 2 & 700 & 100 & 520 & 400 & Yes & $\$ 2,210,000$ & 144,360 & $\$ 4,055,409$ & 0.612 \\
\hline 囷 & 300 & 3 & 700 & 100 & 520 & 400 & No & $\$ 2,220,000$ & 143.700 & $\$ 4,056,969$ & 0.612 \\
\hline 图 & 300 & 3 & 700 & 100 & 520 & 400 & Yes & $\$ 2,220,000$ & 143,700 & $\$ 4,056,969$ & 0.612 \\
\hline 国图 & 300 & 3 & & 100 & 520 & 800 & No & $\$ 2,210,000$ & 144,673 & $\$ 4,059,401$ & 0.613 \\
\hline & 300 & 3 & & 100 & 520 & 800 & Yes & $\$ 2,210,000$ & 144,673 & $\$ 4,059,401$ & 0.613 \\
\hline & 300 & 1 & 700 & 100 & 520 & 800 & No & $\$ 2,210,000$ & 145,065 & $\$ 4,064,414$ & 0.613 \\
\hline & 300 & 1 & 700 & 100 & 520 & 800 & Yes & $\$ 2,210,000$ & 145,065 & $\$ 4,064,414$ & 0.613 \\
\hline & 300 & 2 & 700 & 100 & 520 & 800 & No & $\$ 2,220,000$ & 144,845 & $\$ 4,071,601$ & 0.614 \\
\hline & 300 & 2 & 700 & 100 & 520 & 800 & Yes & $\$ 2,220,000$ & 144,845 & $\$ 4,071,601$ & 0.614 \\
\hline & 300 & 3 & 700 & 100 & 520 & 800 & No & $\$ 2,230,000$ & 144,127 & $\$ 4,072,420$ & 0.614 \\
\hline - & 300 & 3 & 700 & 100 & 520 & 800 & Yes & $\$ 2,230,000$ & 144,127 & $\$ 4,072,420$ & 0.614 \\
\hline 圂 & 300 & 3 & & 100 & 520 & 1200 & No & $\$ 2,220,000$ & 144,938 & $\$ 4,072,797$ & $0.615^{-}$ \\
\hline
\end{tabular}

Figure 5. A short part of optimized data of proposed microgrid system

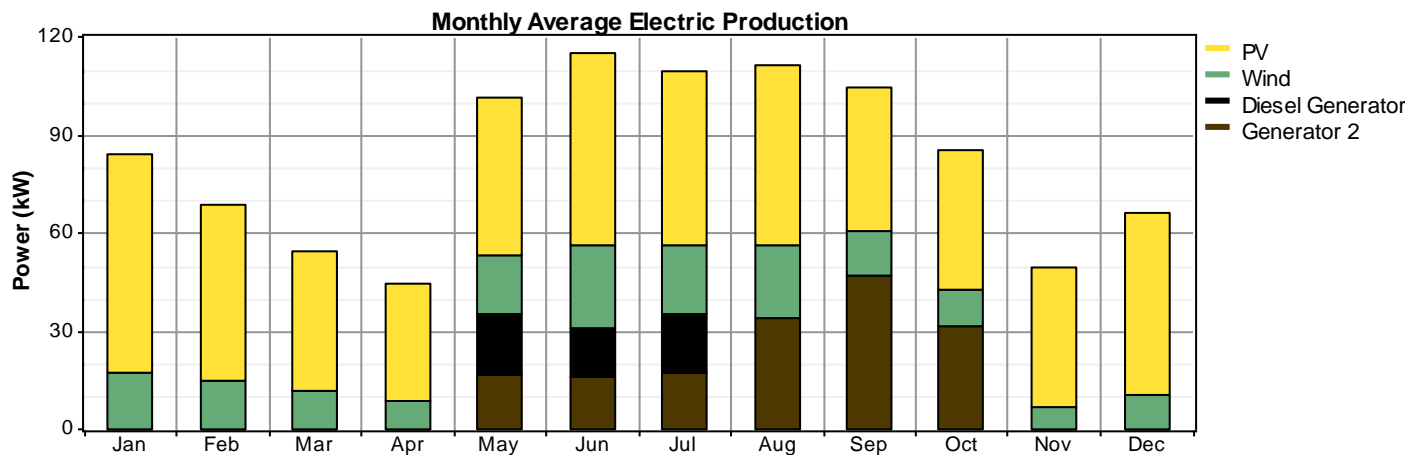

Figure 6. Monthly power production from different sources randomly choose among optimization results

Table 4. Greenhouse gas emissions

\begin{tabular}{|l|r|}
\multicolumn{1}{c|}{ Pollutant } & Emissions $(\mathrm{kg} / \mathrm{yr})$ \\
\hline Carbon dioxide & 10,469 \\
\hline Carbon monoxide & 27.1 \\
\hline Unburned hydrocarbons & 3 \\
\hline Particulate matter & 2.04 \\
\hline Sulfur dioxide & 21 \\
\hline Nitrogen oxides & 241 \\
\hline
\end{tabular}




\section{Conclusion}

The study simulates a PV-wind-diesel-battery hybrid energy system for microgrid in St. Martin's Island. The optimized hybrid energy system was developed considering manufacturing cost and efficiency. The result shows that the cost of energy of the optimized system is $35.26 \mathrm{BDT} / \mathrm{kWh}$ for installation year and it is gradually decreased to approximately 7.56 BDT/kWh. This system gives better performance than the other system because if any fault occur in PV panel or/and in wind turbines in addition biomass then the generator can minimize this problem. This proposed system produces $10469 \mathrm{~kg} /$ year of carbon dioxide which is less than the production from diesel generator.

\section{References}

[1] Biodiversity and Eco tourism project of St Martin's, Bangladesh, Dhaka, (2004).

[2] Electricity demand survey report at the St. Martin's Island, SRE, LGED, Dhaka, Bangladesh, (2004) May.

[3] A Hossain, "Remote Area Power Supply Systems (RAPSS)", IIFC report, (2001).

[4] R. H. Lassseter, "Smart Distribution: Coupled Microgrids", Proceedings of the IEEE, vol. 99, Issue 6, (2011) June, pp. 1074-1082.

[5] S.S. Shi, Z. X. Lu, Y. Min and Y. Qao, "Modeling and simulation of the microgrid prototype in China", presented at the 8th International Conference Advances in Power System Control, Operation and Management (APSCOM 2009), (2009), Kowloon, Hong Kong.

[6] HOMER, V-2.14, National Renewable Energy Laboratory (NREL), USA, http://www.nrel.gov/homer.

[7] NASA surface meteorology and solar energy, released 5.1, http://eosweb.larc.nasa.gov.

[8] S. M. Shaahid and El-Amin, "Techno economic evaluation of off-grid hybrid photovoltaic-diesel-battery power systems for rural electrification in Saudi Arabia-a way forward for sustainable development", Renew Sustain Energy Rev, vol. 13, (2009), pp. 625-33.

[9] C. Marnay and O. C. Baile, "The CERTS Microgrid and the Future of the Macrogrid", Available: http://certs.lbl.gov/pdf/55281.pdf.

[10] R. H. Lassseter, "Microgrids", Power Engineering Society Winter Meeting, New York, (2002).

[11] S. Mizani and A. Yazdani, "Design and Operation of a Remote Microgrid", 35 ${ }^{\text {th }}$ Industrial Electronics Conference, (2009) November.

[12] G. Kyriakarakos, A. I. Dounis, S. Rozakis, K. G. Arvanitis and G. Papadakis, "Polygeneration microgrids: A viable solution in remote areas for supplying power, potable water and hydrogen as transportation fuel", Applied Energy, vol. 88, Issue 12, (2011) May, pp. 4517-4526.

[13] F. Katiraei and M. R. Iravani, "Power management strategies for a microgrid with multiple distributed generation units”, IEEE Transactions on Power Systems, vol. 21, Issue 4, (2006) November, pp. 1821-1831.

[14] S. Mizani and A. Yazdani, "Design and Operation of a Remote Microgrid", 35th Industrial Electronics conference, (2009) November.

[15] N. Amjady, F. Keynia and H. Zareipour, "Short-term load forecast of microgrids by a new bilevel prediction strategy", IEEE Transactions on Smart Grid, vol. 1, Issue 3, (2010) December, pp. 26-294.

[16] N. K. Ardeshna and B. H. Chowdhury, "Supporting islanded microgrid operations in the presence of intermittent wind generation", Power and Energy Society General Meeting, (2010) July.

[17] High Resolution Solar Radiation Assessment for Bangladesh, SWERA project, http://swera.unep.net.

[18] S. Islam, Tidal data at the St. Martin's Island, BUET, Bangladesh, (2004). 


\section{Authors}

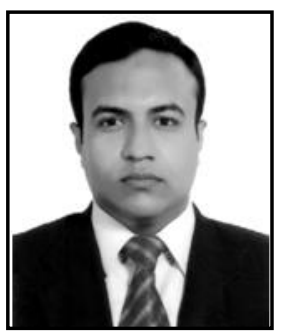

\section{Md. Ruhul Amin}

He has been working as a Lecturer at the Department of Electrical and Electronic Engineering in the University of Information Technology \& Sciences (UITS), Dhaka, Bangladesh since January 2013. He holds Bachelor of Science degree in Electrical and Electronic Engineering with specialization on Power Systems Engineering from UITS'2012, Dhaka. He has numerous national and international publications in his area of skills. His research area concentrates on the issues related to Electrical Power System and Engineering; FACTS, Distributed Generation and Control; HVDC; Renewable Energy; Smart Grid; Power Electronics.

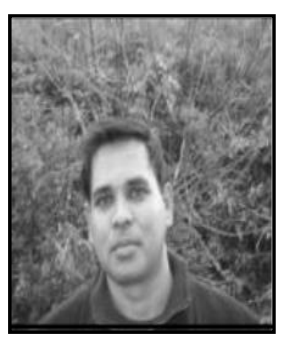

\section{Rajib Baran Roy}

$\mathrm{He}$ has completed Bachelor of Science in Electrical Electronic Engineering from Chittagong University of Engineering and Technology (CUET), Chittagong, Bangladesh and Master's of Science in Sustainable Energy System and Management from University of Flensburg, Germany. He is currently working as an Assistant Professor in the Electrical and Electronic Engineering department of the University of Information Technology and Sciences (UITS), Dhaka, Bangladesh. So far he has five publications in international journals. His research interests are electrical power system analysis, reactive power compensation, hybrid power system, and renewable energy based distributed power system and application of industrial electronics in power system.

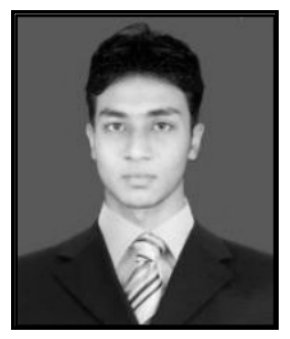

\section{Md. Mahmudul Hasan}

He has been an Asst. Professor at University of Information Technology \& Sciences, Dhaka, Bangladesh since 2010 and before that he was an Asst. Professor at KIIT University since 2009. He holds a Masters of Technology degree in Electronics and Telecommunication with specialization on Communication Systems Engineering, and a Bachelor of Technology degree in Electronics and Telecommunication Engineering from KIIT University, India. He has several national and international publications in his area of expertise. His research area addresses the issues related to wireless communication and network; WLAN, multicarrier and multiuser communications like CDMA, OFDM, MIMO; Wireless sensor networks; Smart Grid and Microstrip antenna. 
International Journal of Energy, Information and Communications Vol.5, Issue 5 (2014) 